\title{
Functions of the Haversian System
}

\author{
DONALD H. ENLOW \\ Department of Anatomy, The University of Michigan, \\ Ann Arbor, Michigan
}

The Haversian system or osteone has been traditionally adopted as a universal unit of structure in compact bone. The basic functions and the structural significance of primary and secondary Haversian tissue, however, are poorly understood. Two explanations on the functional meaning of the secondary Haversian system have been proposed. These are (a) the interpretation of the osteone as an exclusive response to stress, and (b) the interpretation of the secondary osteone as an exclusive structural result of mineral mobilization and redistribution. However, the characteristic absence of the Haversian system in the compact bone of many vertebrate species, including widely used experimental forms such as the white rat, and the characteristic patterns of distribution of Haversian systems in the bone of those species which do possess these structural systems, cannot be entirely explained on the basis of these existing functional concepts. This report will propose that the Haversian system has several basic, previously unrecognized functions.

The bone tissues from a large number of individuals and from a variety of species were studied in an attempt to establish the developmental, functional, and structural relationships which are associated with the process of secondary Haversian reconstruction. It was found that localized or widespread areas of non-pathological osteocyte necrosis can be present as a natural condition in specific types of bony tissue, and that resorptive and reconstructive activity may be associated with such regions. It is suggested that the secondary osteone can function as a replacement mechanism in the internal reconstruction and reorganization of primary bone in cortical areas involving necrosis.

A variety of the secondary osteone, independent of necrosis, is characteristically associated with areas of re-location in muscle attachment on a growing bone, and in remodeling processes involving resorption of periosteal bone surfaces during metaphyseal reduction in diameter and regional changes in shape. The hypothesis is advanced that this type of Haversian system functions as an anchoring mechanism which can maintain muscle continuity and attachment with bone during such remodeling changes. All secondary osteones, regardless of particular function, are structurally comparable and represent a product of internal reconstruction within compact bone.

History. Leeuwenhoek (1678) was the first to notice the microscopic canal system in bone, and he reported his observations to members of the Royal Society in a series of personal communications which were later published. Soon after, Clopton Havers presented several lectures before the Royal Society in which he described in greater detail the microscopic structure of bone and joints. Havers, a versatile English physician, later compiled his extensive observations and published the first monograph, "Osteologia Nova," dealing with the structure and function of bone as a tissue (1691). Havers did not recognize or first identify the Haversian system, but he did describe in some detail the "longitudinal and transverse pores" in compact bone. These were becoming generally known, by the middle of the eighteenth century, as the canals of Havers (Albinus, 1757). Havers suggested that canals in compact bone function to transport medullary oils in order to "mollify" the substance of the bone, and he believed that the canals located near the ends of the bone carry lubricating oils to nearby joints. These logical notions were popularly accepted and persisted for another half a century (Monro, 1763). It is in- 
teresting to remember that one entire school of thought, led by prominent anatomists and physiologists as late as the nineteenth century, denied the existence of any canal system in bone (Bostock, 1825). Several early writers observed blood vessels in the larger spaces of bone, but Albinus (1757) confirmed the presence of vessels in small cortical canals by the use of vascular injection methods. The Haversian system of concentric lamellae with its central canal was described, defined, and named by Todd and Bowmann (1845). The Haversian space (resorption canal) was identified by Tomes and DeMorgan (1853), and these workers were the first to recognize that the Haversian system represents a substitution mechanism. The term "osteone" was introduced by Biedermann ('14), and the hypothesis that the osteone develops as a mechanical response to tension was formulated largely by Gebhardt ('05). Biochemical considerations relative to the interpretation of secondary bone reconstruction have been investigated and discussed by Amprino ('48, '51, '52) and by Ruth ('53). The presence of secondary osteones near a periosteal surface, particularly in bony tuberosities, was noticed by Petersen ('30), and he termed these Haversian systems "marginal osteones" (Randosteonen).

It is well known that necrotic bone tissue can be associated with a variety of pathological processes, particularly those involving vascular interruption. Empty lacunae in areas of dead bone were observed by Barth (1895). Necrotic bone, unrelated to pathological processes and located specifically in interstitial areas (between Haversian systems), was noticed by Mueller ('26), Jaffe and Pomeranz ('34), by Sherman and Selakovich ('57), and by Frost ('60). These workers did not suggest that the Haversian system functions as a specific replacement mechanism in response to the presence of necrosis. By counting proportions of empty lacunae in random microscopic fields, Frost confirmed the proposition that necrotic bone in the human is more frequent in older individuals, and that it is more widespread in extra-Haversian bone. The results of the present study are consistent with these findings. It will be demonstrated that areas of bone necrosis appear in definite patterns of distribution and with predictable structural relationships.

\section{MATERIALS AND METHODS}

Forms studied. Bone tissues from 89 Rhesus monkeys, from 29 dogs, and from survey samples of other representative vertebrate groups were examined for (a) the distribution and structural relationships of primary and secondary Haversian tissues, and (b) the presence and distribution of non-pathological necrosis in compact bone. In order to determine the sequence of Haversian changes and age relationships, observational data of monkey bone tissues were organized according to primary, mixed or permanent dentition. Bone from the femur, tibia, humerus, radius, and mandible was studied in most of the monkeys. Multiple, entire transverse sections were made through many of the bones from their proximal to distal ends.

Experimental necrosis. To test the response of secondary Haversian reconstruction to the presence of necrotic bone, localized areas of diaphyseal bone in the femora of white rats were experimentally necrotized. The bone was exposed by surgical entrance through the lateral intermuscular septum. The periosteum was reflected, and an area measuring about $2 \mathrm{~mm}^{2}$ was necrotized by thermal cautery. The animals were sacrificed at intervals through a period of 6 months. The cauterized areas were then examined histologically and compared with normal bone in the opposite femur and with bone from control animals.

Methods of tissue preparation. Ground thin-sections were made using a powerdriven polishing lap wheel. To demonstrate canalicular calcification in necrotic bone (a process to be considered later), the thin-sections were coated with an impervious seal of parlodion (Enlow, '54), or were impregnated with fuchsin or silver nitrate (Frost, '60). Using these techniques, areas in which canaliculi have been filled with mineral ("micropetrosis") appear transparent and are easily recognized. The transparent nature of this bone is due to the absence of trapped air normally 
present in canaliculi as viewed in ground sections. Ordinary mounting of ground thin-sections in balsam or other standard media without such treatment will give uncertain results, since seepage of the media into unprotected canaliculi may displace the air and thereby prevent differentiation between areas of micropetrosis and areas in which the canaliculi are not filled with mineral. Micropetrosis cannot be recognized in decalcified preparations. Microradiographs were compared with ground sections in order to determine possible differences in radio-density between vital bone and necrotic areas containing canalicular calcification.

Decalcified and stained sections were prepared by standard methods using a microtome. Preparations were also made by a special technique in which ground thin-sections were decalcified and stained (Enlow, '61a). This method gave assurance that necrotic areas were not regions of artifact resulting from poor fixation. Early in the study, sections were prepared from tissue blocks $2-5 \mathrm{~mm}$ thick, but there was still concern that empty lacunae (an indicator of necrosis) might be a result of incomplete fixation. To exclude this possibility, blocks of bone were removed from animals immediately following sacrifice, and polished thin-sections approximately $80-110 \mu$ were prepared and decalcified at once in Decal solution. ${ }^{1}$ They were washed and then placed in $10 \%$ formalin. A paper-thin, completely decalcified section of bone, therefore, was exposed to the fixative in not more than 30 minutes following death. Sections in this range of thickness contain 4 or 5 layers of osteocytes, thereby insuring complete enclosure and protection of cells. Microtome preparations were sectioned at about $50 \mu$, since very thin sections will not demonstrate all nuclei present.

Cellular necrosis in bone. Areas of bone which involve osteocyte necrosis may be identified, in decalcified and stained sections, by the absence of nuclei within lacunae. Using routine methods of preparation, intercellular tissues appear otherwise unchanged. In any local or extensive region of necrosis, most or all of the lacunae within that region are totally devoid of cells.
The presence, distribution, and extent of normal osteocyte necrosis appears to be directly related to the particular arrangement of tissue components involved in the structure of that bone. Areas of bone which are composed predominantly of primary osteones or of a closely-meshed, symmetrical network of primary canals ("Plexiform" bone, fig. 11; Enlow and Brown,'56) seem to be relatively resistant to the appearance of necrosis, since regions of empty lacunae are infrequently observed. The distribution of canals in these tissues is typically dense. Ordinary circumferential lamellar bone which contains a crowded concentracion of primary vascular (non-Haversian) canals also appears resistant to necrosis (fig. 3). The degeneration and subsequent disappearance of osteocytes seems to occur initially at selective focal points which are farthest removed from adjacent vascular canals (fig. 1). In a microscopic section of any bone, the pattern of necrosis depends largely on the amount and pattern of any sparsely vascularized, circumferential lamellar bone which is present in that section. Necrotic bone may appear, thus, as isolated patches (figs. 1,10), or in a widespread circumferential zone (fig. 2). As an area of necrosis becomes enlarged in extent, cells in those regions immediately surrounding canals may also die (fig. 6). In extreme or advanced necrosis, primary osteones and plexiform bone can become involved, although this situation has not often been observed.

Examination of a variety of skeletal elements from the same individual, and of multiple sections made at different levels from the same bone, indicates that the distribution of cellular necrosis is determined by the particular combinations of tissue types present, as described above. In view of the consistent and predictable frequency in the occurrence of necrotic tissue, the presence of limited osteocyte necrosis is considered a normal or natural situation (table 1 ).

Based on these observations, it may be stated that, in general, a greater density in the number of vascular canals in any region of compact bone favors a greater resistance in that particular bone locality

1 Scientific Products, Evanston, Illinois. 
to the death of its osteocytes. Conversely, a sparse distribution or total regional absence of vascular canals is conducive to local cellular degeneration and necrosis. Death in any population of osteocytes is a regional situation which is governed by the pattern and arrangement of component tissue types.

Resorption spaces. Bone tissues in which canals are partially or completely surrounded by a community of living osteocytes but which contain scattered, isolated patches of necrotic bone in interstitial areas between canals, have been observed to demonstrate infrequent, scattered resorption spaces. However, bone tissues containing areas of extensive necrosis in which canals are located directly within necrotic bone and with all surrounding lacunae lacking cells, demonstrate an increased number and distribution of resorption spaces and formative secondary osteones (table 2, figs. $4,5,6,7$ ). It is significant to note that such secondary Haversian formation can be located in regional zones of compact bone which, in individuals of the same species possessing only living bone, characteristically lack secondary osteones. The resorption spaces represent enlarged cavities derived from canals located immediately within the region of necrosis. The fact that necrotic areas can occur prior to resorptive activity (fig. 1) suggests that Haversian replacement is not necessarily an immediate process and that a period of time is in-

TABLE 1

\begin{tabular}{|c|c|c|c|c|c|c|}
\hline & & \multicolumn{4}{|c|}{ Rhesus monkeys } & \multirow{2}{*}{$\begin{array}{c}\text { Dogs } \\
\text { ages } \\
\text { unknown }\end{array}$} \\
\hline & & $\begin{array}{l}\text { Primary } \\
\text { dentition }\end{array}$ & $\underset{\text { dentition }}{\text { Mixed }}$ & $\begin{array}{c}\text { Permanent } \\
\text { dentition }\end{array}$ & $\begin{array}{l}\text { Unknown } \\
\text { dentition }\end{array}$ & \\
\hline \multirow{3}{*}{ Micropetrosis' } & Absent & 17 & 18 & 13 & 13 & 25 \\
\hline & $\begin{array}{l}\text { Scattered patches } \\
\text { (as in fig. 15) }\end{array}$ & $4^{2}$ & 2 & 2 & 4 & 2 \\
\hline & $\begin{array}{l}\text { Extensive } \\
\quad \text { (as in fig. 16) }\end{array}$ & 0 & 4 & 7 & 0 & 2 \\
\hline \multirow{3}{*}{ Necresis } & Absent & 5 & 3 & 0 & 7 & 5 \\
\hline & $\begin{array}{l}\text { Scattered patches } \\
\text { (as in fig. 10) }\end{array}$ & 0 & 3 & 15 & 9 & 20 \\
\hline & $\begin{array}{l}\text { Extensive } \\
\quad \text { (as in fig. 2) }\end{array}$ & 0 & 0 & 3 & 1 & 4 \\
\hline
\end{tabular}

I Specimens examined for micropetrosis were not necessarily checked for osteocyte necrosis, since some bone samples were available only in a dried condition. The total number of specimens for which micropetrosis is reported, therefore, is larger than the number examined for cellular necrosis.

2 Dried specimens. Extent of osteocyte death not known.

TABLE 2

\begin{tabular}{|c|c|c|c|c|c|c|}
\hline \multirow{2}{*}{ Necrosis } & \multirow{2}{*}{$\begin{array}{c}\text { Rhesus } \\
\text { monkeys } \\
\text { number of } \\
\text { individuals } \\
\text { examined }\end{array}$} & \multirow{2}{*}{$\begin{array}{c}\text { Dogs } \\
\text { number of } \\
\text { individuals } \\
\text { examined }\end{array}$} & \multicolumn{2}{|c|}{$\begin{array}{l}\text { Resorption spaces } \\
\text { in necrotic bone }{ }^{1}\end{array}$} & \multicolumn{2}{|c|}{$\begin{array}{c}\text { Resorption spaces } \\
\text { in living bone }{ }^{1,2}\end{array}$} \\
\hline & & & monkeys & $\operatorname{dog} s$ & monkeys & dogs \\
\hline Absent & 15 & 5 & 0 & 0 & 24 & 26 \\
\hline $\begin{array}{l}\text { Scattered patches } \\
\text { (fig. 10) }\end{array}$ & 27 & 20 & 31 & 14 & 92 & 118 \\
\hline $\begin{array}{l}\text { Extensive } \\
\text { (fig. 2) }\end{array}$ & 4 & 4 & 95 & 215 & 8 & 26 \\
\hline \multicolumn{7}{|c|}{$\begin{array}{l}\text { 2Total number of resorption spaces and partially-formed secondary osteones from transverse, mid } \\
\text { diaphyseal sections of the femur in all specimens. Resorption spaces and formative osteones in } \\
\text { areas of musce attachment and in areas produced during endosteal growth are not included re } \\
\text { gardless of necrosis present, since such secondary reconstruction may result from other growth } \\
\text { circumstances. } \\
2 \text { Characteristically located in periosteal bone on or near a reversal junction between endosteat } \\
\text { and periosteal zones of the cortex. }\end{array}$} \\
\hline
\end{tabular}


volved. This is supported by the experimental findings to be described in a later section and by the data presented in table 2. Whether or not "buds" from nearby canals in living bone can penetrate and replace adjacent necrotic bone has not been determined. Observations of blind canals (Dempster and Enlow, "59) suggest this possibility, but it may also be true that such canals represent plugged osteones (Cohen and Harris, '58). Closed canals have been observed in microscopic sections, particularly in areas of extensive necrosis. Lacunae surrounding such canals are typically empty.

Age relationships. The conspicuous absence of major necrotic areas in younger individuals (table 1) can be attributed to the almost exclusive presence of richly vascularized bone. Compact bone in such forms is composed of either closely packed primary osteones, plexiform bone, or of lamellated bone tissue containing a dense concentration of simple, primary vascular canals. As described earlier, these bone types are less sensitive to necrosis than thick expanses of lamellar bone containing only scattered vascular canals. With increased age, and as local growth rates and remodeling alterations result in progressively changing tissue combinations, increased deposits of sparsely vascularized, circumferential lamellar bone accumulates. This latter variety of bone, found in quantity only in individuals beyond very young age, is the tissue type most commonly associated with necrosis. During periods of active skeletal growth, new cell populations are constantly being added and older cell communities are being removed as bones change in size and regional shape. When adult proportions are reached, this process becomes slowed so that subsequent changes within compact bone proceed largely by internal Haversian replacement.

Placement of secondary osteones. Conforming with the distributional pattern observed in the arrangement of resorption canals, secondary Haversian systems are selectively positioned in either regional or extensive areas of necrotic bone (figs. 4, $5,6,7)$. Deposition of concentric lamellae within resorption canals will convert these spaces directly into secondary oste- ones. The secondary osteone, thus, appears to be a structural product following the superimposition of a newly formed population of living bone cells within older regions of localized dead bone. Remnants of former necrotic bone which are not completely replaced now persist as dead interstitial bone tissue between Haversian systems (figs. 6,7 ).

Currey ('60), in comparing the blood supply of Haversian and plexiform bone, comments that Haversian bone is less "efficient" than the latter. This conclusion is consistent with the observations reported in the present study. Currey speculates that the presence of previously established Haversian systems may cause the eventual death of surrounding interstitial cells and that this would be followed by an increase in the number of secondary osteones produced during progressive replacement. It has been assumed by earlier workers that the relative immunity of the Haversian system to necrosis, compared with interstitial bone, is attributable to the isolation of interstitial tissue from its vascular supply (Mueller, '26; Jaffe and Pomeranz, '34; Frost, '60). That the proximity of the vascular supply is a significant factor in the presence of necrosis has been discussed, and this situation is true also for the Haversian system. However, the characteristic, selective localization of resorption canals and secondary osteones within necrotic bone, which was previously primary in nature, strongly supports the replacement interpretation of this secondary tissue.

With the continued reappearance of necrosis, secondary osteones themselves may succumb to osteocyte death. These are then partially replaced by newer systems (fig. 17), and second and third generations of superimposed Haversian systems are thereby produced.

Species correlation. Growth rate in conjunction with animal size and longevity determines the particular combinations of basic bone tissue types found in the skeleton of any vertebrate species. Examination of bone tissues from a variety of representative vertebrates indicates that species having bone tissues composed largely of tissue types which are more resistant to necrosis, as described above, 
do not possess significant amounts of true secondary Haversian tissue in periosteal layers of the cortex. Examples would include most amphibians, some reptiles, and a great many smaller mammals, such as the white rat. Conversely, species which characteristically have more massive deposits of circumferential lamellar bone containing a relative deficiency of vascular canals, as in portions of the human skeleton, commonly possess more or less extensive areas of secondary Haversian bone. Even in older human bone, however, much primary although densely vascular bone can be found. Secondary Haversian tissue, in any species typically exhibiting this particular bone type, can be arranged in isolated clusters or as extended zones depending on the pattern and extent of necrosis.

Experimental evidence. To test experimentally the response of secondary Haversian reconstruction to the presence of aseptic necrosis in a species which does not normally have either widespread bone necrosis or secondary Haversian systems, small areas of cortical bone in the white rat were necrotized by thermal cautery. An encrusting callus developed around the periphery of the necrotic area and eventually covered it. The initial stage of the callus involved the formation of fine cancellous, non-lamellar bone with subsequent lamellar compaction. Immediate, extensive resorption and replacement of necrotic bone did not take place. Within the six-month period, typical scattered resorption canals had appeared within areas of necrosis, and concentric lamellar deposition within these spaces was observed (fig. 26). This is the same formative sequence involved in secondary Haversian formation.

The results of this experiment must be interpreted in perspective. The experiment performed by Ruth ('53) demonstrated that secondary osteones can develop in the rat by artifically induced, severe calcium deprivation (causing resorption) followed by a period of dietary calcium excess (available calcium for regenerative redeposition). This work demonstrates how secondary osteones can develop under controlled conditions. It does not, however, define natural circumstances which determine why they do or do not develop, since the rat normally does not possess secondary Haversian systems whereas certain other species do. To say that the functional significance of the Haversian system is a singular result of calcium need and mobilization followed by redeposition would be overextending the conclusions of Ruth's study, which the author did not intend since his purpose was to demonstrate the osteone as a mechanism of replacement. Similarly, the parallel response to cautery-induced necrosis demonstrates a laboratory circumstance which can produce secondary reconstruction. In itself, this does not confirm that the Haversian system is a unique result of regeneration following necrosis. It does, however, indicate that the observations described in this study can be reproduced experimentally.

Canalicular calcification. In association with natural necrosis, a normal condition can be present which unvolves the deposition of mineral within canaliculi.

Soon after the surprisingly recent discovery of lacunae by Deutsch and Purkinje in 1834 (Leeuwenhoek may have seen them in the late 1600's but his descriptions are vague), there was much speculation concerning their contents. It was suggested by Muller (1834) and Miescher (1836) that the lacunae with their canaliculi are filled with chalk ("sacculi and canaliculi chalicophori"). Bruns (1841) and Gerlach (1848), using injection techniques, demonstrated that they are hollow in ground sections and suggested that they contained plasma in living bone. Lessing (1846) showed that lacunae and canaliculi appear dark in dried thin-sections due to the presence of air, and he argued that they represent an air-filled lacunar system in life. But during the same period, the cell doctrine was becoming established. The presence of nuclei and cytoplasm in the lacunae of cartilage was identified by Schwann (1837), and cells located in the lacunae of bone were reported by Mayer (1841) and by Donders (1848). Tomes (1843) confirmed the cellular nature of bone tissue, but he also recognized and reported that many canaliculi can be filled with mineral. This observation was recently rediscovered by Frost ('60), who 
correctly related canalicular calcification with osteocyte death. He has termed this process "micropetrosis." Calcified canaliculi appear to be comparable with sclerotic or transparent dentin (Orban, '57), in which dentinal tubules within dead tracts are plugged with mineral deposits.

Patterns of distribution and structural relationships. Areas of micropetrosis can appear (a) in interstitial bone (figs. 17, 24), (b) as isolated patches (fig. 15), or (c) as extensive circumferential zones or layers (figs. 16, 18). Micropetrosis, when present, may often be recognized macroscopically on cut surfaces of bone by its transparent appearance. The initial onset of micropetrosis appears in restricted spots located within thick lamellar bone containing relatively few vascular canals. Calcification near canals seems to be avoided until the extent of the micropetrosis becomes more widespread (fig. 16). Microradiographs of micropetrotic bone (figs. 20, 21 ) show that the overall density of the matrix, when compared with adjacent areas of vital bone, is not noticeably affected in the bone of the young, growing individuals examined.

Both resorption spaces and secondary osteones are frequently and characteristically located in areas of micropetrosis (figs. 15, 18, 19, 24). Interstitial micropetrotic bone between secondary osteones represents the remnants of older necrotic tissue (fig. 17).

It is apparent that the distribution of canalicular calcification coincides both in pattern and structural relationships with necrosis. Necrosis, sometimes even rather widespread in extent, can be present in a bone, yet that same bone may or may not show micropetrosis. Apparently, calcification of canaliculi is a sequel to necrosis.

Relationship of secondary reconstruction with gross remodeling. The progressive remodeling of a bone during its postnatal growth involves considerable reorganization and alteration in the minute structure of the bone tissue itself (Enlow, '61b). Detailed analysis of this remodeling process makes possible a developmental interpretation of the complex architectural patterns and structural combinations observed (a) in different areas of the same bone, (b) in different bones of the same individual, (c) in different ages of the same species, and (d) between different species. The formation of the true secondary osteone, which is concerned with the internal reconstruction of compact bone, can also be involved in general remodeling processes concerned with the gross shaping of bone during growth. The development of this particular variety of the Haversian system may be quite independent of necrosis.

Secondary Haversian formation regularly occurs in defined areas, so that distinct "Haversian zones" can be identified. The shifting of zones following gross remodeling changes will often result in the relocation of such Haversian zones into new positions within the cortex. Haversian bone associated with muscle re-attachment, for example, and with endosteal growth or with cancellous compaction, can come to lie deep within the cortex in a new relationship at some distance from its former location.

Bone structure in areas of muscle attachment. The composition and arrangement of bone tissue within prominent processes, depressions, or unmodified bone surfaces to which muscles or tendons attach can be distinctive. Within such regions, concentrations of secondary osteones are observed as a characteristic and localized component (figs. 8, 23). The initial formation of these secondary systems is not a response to necrosis, although this process can also be involved as independent complication (fig. 12).

During longitudinal growth of a bone, muscle attachment necessarily becomes shifted as a muscle is relocated in its migration up or down the elongating shaft. Also, the sectional shape of a bone undergoes considerable change during metaphyseal-diaphyseal transition. If tubercles are involved, a continual "drift" in the relative location of the tubercle takes place during remodeling. Continuous release of muscle insertion is required in this process, and progressive muscle reattachment must be maintained during such growth changes. There is no problem if the shift in location involves simply periosteal deposition of new bone enclosing new Sharpey's fibers. But if muscle attachment is to be preserved on a sur- 
face undergoing active resorption rather than deposition, the continued insertion of that muscle must survive even though the bone into which the muscle is attached is being removed. If rate of growth is relatively slow, this is apparently accomplished by waves of localized resorption and surface apposition, so that at least parts of a muscle are anchored at any one time. The process involved has been discussed by Petersen ('30). In species which show periods of rapid skeletal growth, however, the structural arrangement illustrated in figure 13 is common. The tubercle is drifting across the surface of the bone. One side of this bony process has received lamellar apposition whereas the opposite side is a resorptive surface. Muscle attachment must be maintained on a resorptive as well as on the depositional surface. While periosteal attachment is not necessarily completely severed during periods of periosteal resorption, the muscle nevertheless must be relocated and re-attached on this resorptive surface. The resorptive enlargement of canals in the underlying compacta and subsequent deposition of new bone within these canals can serve to reestablish intimate periosteal bond with the substance of the bone, even though the surface of that same area is being progressively destroyed. The whole substance of the osteone is in direct contact with the periosteum since the fibrous matrix of the entire Haversian cylinder is continuous with the fibrous component of the periosteum. In figure 13 , the secondary osteones follow in the direction of the drift but are in advance of the resorptive surface. In this situation, the secondary Haversian system appears to represent a pinning or pegging mechanism which can serve to anchor the muscle to that area of bone which is itself undergoing removal, or within which the attachment of a muscle is shifting in location. A comparable process will be discussed below in connection with endosteal bone growth during metaphyseal remodeling.

Compaction of coarse cancellous bone. Reduction in diameter of the bone during metaphyseal and diaphyseal remodeling involves the lamellar compaction of coarsecancellous bone. This is a process of endosteal growth in combination with corresponding periosteal resorption. Spongy bone in the medulla of the metaphysis is converted into compact, cortical bone as the metaphysis is relocated in position to become the diaphysis. Considerable remodeling and internal reconstruction can be involved. The original trabeculae of fine-cancellous endochondral bone are partially removed and replaced by lamellar trabeculae of coarse-cancellous bone. This coarse-cancellous bone itself is subject to extensive removal, replacement, and structural readjustment. Reversals in direction as the bone grows outward, inward, and then outward, together with the formation and reformation of trabeculae and the closure, reopening, and reclosure of cancellous spaces during these growth reversals, produce complex patterns of microscopic architecture. When individual trabeculae are incorporated into the cortex by compaction during inward growth, the resulting compact bone often has a brecciated structure with unorganized, abrupt angles of lamellar orientation. Incomplete segments or vestiges of lamellae are embedded within the former trabeculae, and spaces of widely varying sizes showing progressive stages of compaction are present (figs, 14, 25). Structural results produced by this process of cancellous compaction are associated only with endosteal growth, as coarse-cancellous bone is not involved in periosteal appositicn. The structure is a mosiac of osteones, demonstrating a variety of irregular shapes, proportions, and sizes. This characteristic type of bone can usually be recognized by these features, in addition to the convoluted, whorled configuration always present in the interstitial bone (fig. 14). The canal system, following compaction, may be classed as "Haversian" since each canal is surrounded by a concentric, often irregular, lamellar sheath. Since reconstruction is involved to a greater or lesser degree in the formation of this bone type, it is to be considered as secondary in nature. Regeneration of necrotic bone is not involved in its original formation, but like other bone tissues, it is also subject to this process. Endosteal Haversian bone resulting from coarse cancellous compaction is frequently found in routine section 
preparations. It is typically a significant structural component in the compact bone of larger species having a thick cortex. When persisting in the middle third of a long bone, it occurs in well marked zones which are usually enclosed on one or both sides by more recently formed periosteal and endosteal layers.

The problem of muscle attachment during metaphyseal remodeling. It is apparent that the resorption of an external surface complicates the process of re-attachment during endosteal growth periods involving muscle relocation. This situation is similar to that previously discussed relative to shifts in location of muscle attachment and to tubercle drift in the elongating shaft. In figure 27, metaphyseal diameter is being reduced by external resorption in combination with endosteal apposition. Resorption spaces have formed in front of the inwardly advancing external surface, and lamellar deposition within these spaces has proceeded progressively in an endosteal direction. Note also that the "secondary" canals become abruptly "primary" toward the inner part of the cortex. This process appears to be a mechanism providing progressive periosteal anchorage or continuity within the substance of the compact bone. The entire cylinder wall of each Haversian system is directly continuous with the fibrous matrix of the periosteum. The interstitial bone, thus, is endosteal, but the network of osteones embedded in this endosteal bone is periosteal in nature. Progressive lamellar deposition in each osteone, and the subsequent formation and reformation of new osteones, serves to provide continual periosteal attachment as the periosteal surface itself is being removed. Following reversals in direction of growth, this accumulation of osteones will remain in the cortex as defined zones enclosed by other layers composed of different tissue types. The bone illustrated in figure 28 is entirely endosteal. Note the inner circumferential lamellae, the inward-advancing secondary periosteal osteones, and the external resorptive surface. The section illustrated in figure 29 demonstrates the relationships of such bone following outward reversal in direction of growth. Outer circumferential lamellae now enclose a distinct "zone" of older endosteal bone containing secondary osteones. Remnants of such zones following extended increase in diameter are seen in figures 15 and 16 on the inner margin of the cortex. Secondary osteones are commonly observed to overlap reversal lines separating broad zones produced by inward and outward growth. Haversian systems located within both periosteal and endosteal bone near such a junction are continuous, thereby providing continuity between these two zones (table 2).

Reduction in metaphyseal diameter involving compaction of coarse-cancellous bone will produce interstitial bone which is characteristically whorled and convoluted, as previously described. Even when this bone becomes relocated from its original position to become a zone embedded in the cortex which is located farther down the shaft, it can be identified and its developmental relationships can be recognized. If inward growth takes place in areas of the metaphysis located near the diaphysis, however, cancellous compaction may not be involved. In this situation, endosteal apposition is in the form of extended sheets of inner circumferential lamellae, and following Haversian reconstruction during inward growth, these more regularly arranged lamellae become interstitial in position. The "whorled" appearance, therefore, is not characteristic, and recognition of this bone as endosteal in nature is somewhat more difficult than in other locations which involved cancellous compaction. That it is endosteal, however, can be confirmed by tracing serial sections which demonstrate the direct continuity between these two varieties of secondary Haversian bone tissue produced as a result of inward growth.

The classical pattern of bone structure, involving outer and inner circumferential lamellar layers enclosing a middle Haversian zone, can be one result of this remodeling sequence. In figure 22 the inner layer of circumferential lamellae and the middle zone of secondary Haversian bone were both produced during inward growth. Following reversal, the outer layer of circumferential lamellae was added. It is to be emphasized that the occurrence of 
periosteal resorption in combination with endosteal deposition is widespread during the remodeling of the proximal and distal thirds of the bone. The resulting arrangement of structure may persist in the cortex as these areas later become relocated into the middle regions of the shaft, as in figure 22, following increase in the overall length of the bone. The consistent and predictable relationship of the secondary osteone with this particular remodeling process, as well as with its specific presence in areas of muscle relocation, supports the interpretation of the secondary Haversian system as a functional mechanism providing progressive muscle anchorage during remodeling changes.

\section{DISCUSSION}

The primary osteone. This variety of the Haversian system (fig. 9) is formed by the deposition of concentric lamellae within tubular, anastomosing spaces located in surface deposits of fine-cancellous, non-lamellar bone. Secondary resorption and reconstruction of pre-existing bone is not involved. Although similar in structural appearance, primary and secondary osteones represent different functional systems within compact bone. The primary osteone appears to be associated with either regional or widespread areas involved in the relatively rapid accumulation of bone. The extent of its presence seems to be determined by the body size of the individual and rate of skeletal growth. The primary osteone is quite common, for example, in the skeleton of the young, growing dog and monkey, but although present, it is relatively limited in the white rat. Primary osteones are arranged into distinct zones which have become enclosed by additional zones of different bone tissue types. Clusters of these structures may be observed within tubercles, crests, and other bony processes. Their presence in such locations appears to be a response to growth circumstances rather than a direct adaptation to tension forces in the traditional sense that "Haversian systems" develop and become oriented in patterns determined by lines of stress.

Plexiform bone, a basic variation in the primary pattern of bone structure, is rather common in many species, in- cluding the dog (fig. 11). It is comparable with the primary osteone in that it develops by lamellar filling in fine cancellous spaces which were formed within variable amounts of non-lamellar bone. Rather than forming anastomosing, elongated osteones, however, the canals are arranged as a closely meshed, symmetrical plexus. Like the pirmary osteone, it is observed to develop in areas of rapidly forming bone, and when present, it is usually distributed in widespread areas of the cortex. Plexiform bone is commonly associated with periosteal apposition, but this type of bone has also been observed within deposits produced during endosteal growth.

The secondary osteone. Unlike most tissues, bone contains cells which are entombed in isolated lacunae within a calcified matrix. Adjacent lacunae are interconnected only by canaliculi, and vascular supply can be far removed from cells. It has long been known that osteocytes do not undergo mitotic cell division (v. Ebner, 1875; Broesike, 1882). The repopulation of any local area in bone with a new generation of osteocytes, as in the regeneration of necrotic bone tissue, cannot stem from the mitotic division of adjacent cells already present. Rather, regeneration can only proceed by (1) removal of bone through the formation of resorption canals, and (2) reformation of young bone by lamellar deposition within these erosion canals. The structural result is a secondary osteone composed of concentric Haversian lamellae enclosing a central Haversian canal.

The true secondary osteone has a restricted but predictable distribution in (a) the variety of vertebrate species which have this special type of bone, and (b) the extent in compact bone of those species which do possess secondary osteones (Foote, '16; Amprino and Godina, '47; Enlow and Brown, '56, '57, '58). A great many species lack both the primary and the secondary osteone, and their bone tissues contain primary vascular (non-Haversian) canals only. In certain groups, bone may even be virtually non-vascular. Many species possess bone tissues which are composed of mixed bone containing both primary osteones and primary vascular 
canals. Only a relatively few vertebrate forms have true secondary osteones as a component structure in their bone tissues, and even then, their skeleton may contain regionally massive amounts of primary bone at all age levels. When secondary Haversian systems do occur, they are always found in predictable locations and patterns of distribution.

The nature of this distribution makes it difficult to explain the function and significance of the secondary osteone. Any inclusive explanation must satisfy the distribution outlined in the previous paragraph.

Several conclusions become evident. First, the designation of the Haversian system as a universal unit of structure is unwarranted, even if both primary and secondary osteones are considered. Second, one may question the broad generalization that the presence and the orientation of the Haversian system represent a direct adaptation to patterns of physical stress. Many vertebrate species do not possess these structures yet they are subject to the same mechanical forces in their skeleton as forms which do have secondary osteones. Similarly, mineral redistribution can only represent a partial explanation of the osteone relative to secondary reconstruction within compact bone. The observations reported by Amprino ('52) suggest that secondary reconstruction can be involved in calcium mobilization, particularly in older individuals. However, the total absence of secondary osteones in numerous species, including many having a long life span, together with the characteristic distribution of secondary osteones in particular and predictable relationships and locations when present in the cortex, indicates that secondary reconstruction is not restricted to this biochemical function.

Variation in the types of Haversian systems. It is apparent that the formation of the Haversian system does not represent a single developmental or functional circumstance. The situation is complex in that several varieties of the osteone, as previously described, exist in compact bone. The structure of each, however, is essentially comparable since the osteone itself, regardless of developmental factors involved, is a structural system involving the deposition of bone within a confined space.

The distribution of most Haversian bone tissues observed in this investigation may be accounted for by combinations of (1) the primary osteone, (2) the secondary osteone associated with replacement of necrotic bone, (3) the secondary osteone produced by the compaction of coarse- cancellous bone during endosteal growth, (4) the secondary osteone concerned with muscle relocation, and (5) the secondary osteone produced during inward growth involving periosteal resorption and metaphyseal remodeling. That the utility of the osteone extends beyond the developmental and functional circumstances recognized in this study is suspected because of the inherent versatility of the Haversian system itself. Studies are now needed on (1) specific correlation between aging in bone tissue and corresponding mineral availability and release mechanisms, (2) biochemical relationships of calcium mobilization in the different varieties of bone tissue, and (3) diffusion or permeability rates in the calcified bone matrix.

The non-Haversian canal system in bone. One of the most widely distributed types of vascular canals in compact bone is the simple non-Haversian canal (figs. 1,3 ). It is not surrounded by an individual sheath of concentric lamellae, either primary or secondary. This canal type appears in all but a very few vertebrate groups and at all age levels. It is the typical canal present, for example, in the cortex of the white rat and other laboratory rodents. The non-Haversian canal is found in widespread areas of monkey compact bone and in significant numbers within human cortical bone, even in the aged skeleton. This canal type, strangely, has remained virtually unknown to the general histologist. The non-Haversian canal is termed simply a "primary vascular canal" in this report to distinguish it from both primary and secondary osteones.

In view of its extensive distribution in the bone of most vertebrates, and because of its presence in significant quantities in the bone of many common experimental animals, an increased recognition of the primary vascular (non-Haversian) canal 
as a major structural component of bone is urged.

Osseous necrosis. The present report is primarily concerned with the functional significance of the Haversian system and not with a detailed cytological study of necrosis in bone. Interest in the process of necrosis itself, however, has led to a preliminary examination of necrotic bone at the cellular level. The results of this work are being continued and expanded as a separate cytochemical study.

Bone sections containing areas of necrosis were stained with oil red $O$ in order to determine the extent of neutral fat accumulation within osteocytes. Scattered throughout compact bone, many individual bone cells were found to contain fatty inclusions which largely obscured or displaced other cytological components. Patterns of distribution and tissue relationships, however, were not recognizable with certainty from the preparations at hand. Bone section containing necrosis were also stained with PAS. Differences in the intercellular organic matrix between contiguous living and necrotic zones were not evident using this procedure. The bone samples examined, however, were from Rhesus monkeys having mixed dentition, so that any necrosis present must represent a relatively recent development. Possible matrix changes in necrotic bone of long standing are not known.

A great deal of information is needed on the metabolic circumstances involved in osteocyte death and the resulting influence on surrounding intercellular matrix. It is possible that the disappearance of a community of bone cells does not necessarily result in an immediate, total necrosis of the remaining interstitial tissue in this area, since some interchange between ground substance and collagen with circulating canalicular and lacunar tissue fluids might survive. This situation may parallel the normal decrease in fibroblast population within aging connective tissues. A limited distribution of cellular necrosis in bone may be physiologically compatible with surrounding areas possessing vital cells, but calcareous deposits within communicating canaliculi would subsequently produce a metabolic isolation of acellular regions. With continued plug- ging of canaliculi, the spread of necrosis to adjacent regions of living tissue would be encouraged by the blocking of supply channels. The result would be a progressive enlargement of necrotic zones.

It is evident that necrosis and canalicular calcification are intimately related, but a full understanding of the relationship, as well as the fundamental nature of osseous necrosis itself, is lacking.

\section{ACKNOWLEDGMENTS}

This work was supported by the United States Pubic Health Service, Grant D-1123, and by the Upjohn Company. A large number of bone specimens from normal, untreated Rhesus monkeys were provided by Dr. Paul Ayres, Parke, Davis and Company, Rochester, Michigan. Bone specimens from monkeys of known age were supplied by Dr. James A. Gavan, Anatomy Department, Medical College of South Carolina, and by Dr. G. van Wagenen, Department of Obstetrics and Gynecology, Yale University. Bone samples from a variety of vertebrate forms were provided by Dr. E. T. Hooper and Dr. N. E. Hartweg of the University of Michigan Museum of Zoology.

\section{SUMMARY AND CONCLUSIONS}

1. The secondary osteone is regarded as a structural adaptation to a variety of functional and developmental circumstances. Secondary Haversian reconstruction is a mechanism which provides internal tissue replacement within compact bone yet which does not disturb the gross form of the bone.

2. The secondary Haversian system appears to be concerned with a process of replacement or regeneration in areas involving extensive, natural, non-pathological osteocyte necrosis.

3. Normal osteocyte necrosis is characteristically associated with particular types of bone tissue structure. Bone varieties possessing a sparse distribution of vascular canals are most sensitive to the appearance and spread of necrosis. Bone tissues containing a dense concentration of canals are more resistant to the onset of necrosis.

4. A bone is usually composed of several basic varieties of tissue. The distribution of cellular necrosis in any part of a 
bone, or at any age level, can be either widespread or restricted to scattered patches depending on the distribution and extent of component tissue types which are more susceptible to necrosis.

5. Bone from very young individuals of certain species, and from all age levels of many other species, are composed of densely vascular bone tissues. These forms do not have widespread cellular necrosis, nor do they posses a widespread distribution of secondary Haversian systems in periosteal bone deposits.

6. An increased distribution of resorption canals and secondary osteones were observed in areas of extensive necrosis. Secondary reconstruction in periosteal bone is not marked when necrosis is confined to scattered, interstitial regions.

7. A noticeable degree of canalicular calcification has been observed in a significant number of bone samples which display necrosis. The presence of both extensive and restricted necrosis in many bones which have not experienced canalicular calcification, however, suggests that this process follows rather than triggers the first appearance of osteocyte death. Detailed relationships between the process of mineral deposition in canaliculi and with necrosis have not been established.

8. A distinctive type of secondary osteone is involved in the compaction of coarse-cancellous bone during growth reversals in metaphyseal-diaphyseal remodeling. This variety of the Haversian system is distinguished by the convoluted contours and brecciated construction of interstitial bone located between Haversian systems of irregular shape and size. Reconstruction of necrotic bone is not necessarily involved in the original formation of this type of secondary osteone.

9. The hypothesis is advanced that the secondary osteone functions as a muscle anchoring structure during shifts in the location of muscle attachment produced by growth changes and in tubercle drift.

10. The secondary osteone appears to function as a periosteal and muscle securing mechanism during the active resorption of external bone surfaces. Widespread periosteal resorption is involved in the reduction of metaphyseal diameter during gross remodeling.

11. It is emphasized that bone is composed of a wide variety of basic bone tissue types, and that each type represents a structural response to a particular regional situation. This important generalization must be considered in all experimental and descriptive studies dealing with bone as a tissue.

\section{LITERATURE CITED}

Albinus, B. S. 1757 Academicarum annotationum. 3: 23-24.

Amprino, R. 1948 A contribution to the functional meaning of the substitution of primary by secondary bone tissue. Acta. Anatomica, 5 , part, 3: 291-300.

- 1951 Relations entre la structure et la physiologie de l'os. Ann. Soc. Rouale Sc. Med et Natur. de Bruxelles, 4, part, b: 209-225.

- 1952 Rapporti fra processi di ricostru zione e distribuzone dei minerali nelle ossa. I Richerche esequite col metodo di studio dell'assorbimento dei raggi roentgen. Seischrift fur Zellforschung, 37: 144-183.

Barth, A. 1895 Histologische Untersuchungen uber Knochentransplantationen. Beitr. Path. Anat., 17: 65-142.

Biedermann, W. 1914 Handbuch der Vergleichenden Physiologie. By H. Winterstein.

Bostock, J. 1825 An elementary system of physiology. Wells and Lilly, Boston, I.

Broesike, G. 1882 Uberdie feinere Struktur des normalen Knochengewebes. Arch. Mikrosk. Anat., 21: 695-765.

Bruns, V. 1841 Lehrbuch der Allgemeinen. Anatomie des Menschen.

Cohen, J., and W. H. Harris 1958 The threedirnensional anatomy of Haversian systems. J. Bone and Joint Surg., 40-A, No., 2: 419-434.

Currey, J. D. 1959 Differences in the tensile strength of bone of different histological types. J. Anat., 93, part, 1: 87-95.

1960 Differences in the blood-supply of bone of different histological types. Quart. Jour. Micro. Sci., 101, 3, 351-370.

Dempster, W. T., and D. H. Enlow 1959 Pat. terns of vascular channels in the cortex of the human mandible. Anat. Record, 135, No., 3: 189-205.

Deutsch, C., and Purkinje 1834 De penitioni ossium structura observationes.

Donders, F. C. 1848 Hollandische Beitr. Anat. u. Physiol. Wiss., I.

Ebner, V. V. 1875 Uber den feineren Bau der Knochensubstanz. Bd. der Sitzgsber. Akad. Wiss., JII, 72: 49-138.

Enlow, D. H. 1954 A plastic-seal method for mounting sections of ground bone. Stain Tech., 29, 1: 21-22.

1961a Decalcification and staining of ground thin-sections of bone. Stain Tech., 36, 4: 250-251. 
1961b A study of the post-natal growth and remodeling of bone. Am. J. Anat., in press.

Enlow, D. H., and S. O. Brown 1956 A comparative histological study of fossil and recent bone tissues. Part 1. Tex J. Sci., 8, No., 4: $405-443$.

1957 A comparative histological study of fossil and recent bone tissue. Part II. Tex. J. Sci., 9, No., 2: 186-214.

1958 A comparative histological study of fossil and recent bone tissue. Part III. Tex. J. Sci., 10, No., 2: 187-230.

Frost, H. M. 1960 In vivo osteocyte death. J. Bone and Joint Surg., 42-A, No., 1: 138-143. 1960 Micropetrosis. J. Bone and Joint Surg., 42-A, No. 1: 144-150.

Havers, C. 1691 Osteologia nova. London.

Jaffe, H. L., and M. M. Pomeranz 1934 Changes in the bones of extremities amputated because of arteriovascular disease. Arch. Surg., 29: $556-588$.

Leeuwenhoek, A. 1678 Microscopical observations of the structure of teeth and other bones. Phil. Trans. Roy. Soc., London, 12: 1002-1003. 1693 Observations on the texture of the bones of animals compared with that of wood. Phil. Trans. Roy. Soc., London, 17: $838-843$.

Lessing, S. 1846 Uber ein Plasmatisches Gefassystem in allen Geweben insobesonders in Knochen und Zahnen. Hamburg.

Mayer, G. H. 1841 Uber die Bedeutung der Knochenkorperchen. Mullers Arch., 210-215.

Miescher, F. 1836 De inflammatione ossium. Berlin.

Monro, A. 1763 The anatomy of the human bones. Edinburgh.

Muller, J. 1834 Osteologie und Myologie. Abh. Berl. Akad. Wiss.
Muller, W. 1926 Uber das verhalten des Knochengewebes bei herabgestzer Zirkulation und das Bild von Nekrose der Zwischenlamellen. Beit, z. Klin. Chir., 138: 614-624.

Murray, P. D. F. 1936 Bones. Cambridge University Press.

Orban, B. J. 1957 Oral histology and embryology. C. V. Mosby Co., St. Louis, 4th ed.

Petersen, H. 1930 Die Organe des Skeletsys: tems. Handbuch der Mikroskopischen Anatomie des Menschen, herausgegeben von $\mathrm{V}$. Mollendorff. Berlin. Zweiter Teil, 604-616.

Ruth, E. B. 1953 Bone studies. II. An experimental study of the Haversian-type vascular channels. Am. J. Anat., 93: 429-456.

Schwann, T. 1937 Microscopical researches. Sydenham Society, London.

Sherman, M. S., and W. G. Selakovich 1957 Bone changes in chronic circulatory insufficiency. J. Bone and Joint Surg., 39-A: 892901.

Smith, J. W. 1960 Collagen fiber patterns in mammalian bone. J. Anat, 94, Part, 3: 329344.

1960 The arrangement of collagen fi bers in human secondary osteones. J. Bone and Joint Surg., 42-B, No., 3: 588-605.

Todd, R. B., and W. Bowmann 1845 The physiological anatomy and physiology of man. Blanchard and Lea, Philadelphia.

Tomes, J., and C. De Morgan 1853 Observations on the structure and development of bone. Phil. Trans. Roy. Soc., London, 143, part, 1: 109-139.

Vigliani, F. 1955 Accriscimento e rinnovamento strutturale della compatta in ossa sotratte alle sollecitajinci meccaniche. Zeitschrift fur Zellforschung, 43: $17-47$.

Winslow, J. B. 1734 Exposition of the structure of the human body. Translated by $G$. Douglas, M. D., London.

\title{
PLATE 1
}

\author{
EXPLANATION OF FIGURE
}

1 Osteocyte necrosis $(x)$ in regions between primary vascular (non-Haversian) canals. Lacunae in necrotic areas lack cells. Shadows appear in some of the empty lacunae and do not represent nuclei. Living cells may be identified by the presence of a distinct darkly staining nucleus. Cells located in close proximity to canals have survived. Femur, Rhesus monkey. $112.5 \times$. Decalcified and stained ground-section. 
FUNCTIONS OF THE HAVERSIAN SYSTEM

PLATE 1

Donald H. Enlow

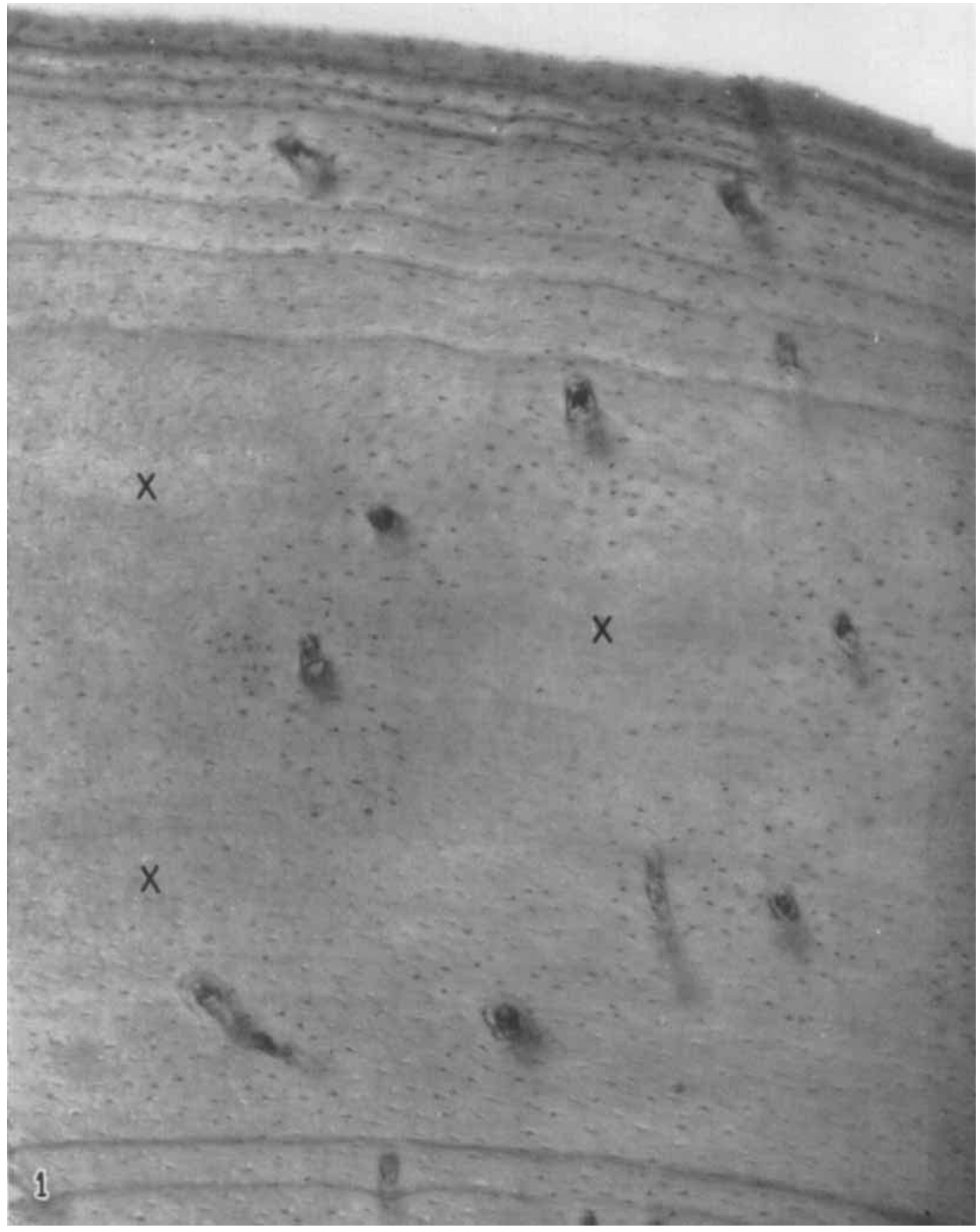


PLATE 2

\section{EXPLANATION OF FIGURES}

2 Necrosis ( $x$ ) in a sparsely vacularized zone in circumferential lamellae. Living osteocytes are present in those lacunae close to the primary vascular canals. Humerus, Rhesus monkey, $62 \times$. Decalcified and stained ground-section.

3 Primary, non-Haversian canals in compact bone. Cellular necrosis is absent. This variety of bone tissue is widely distributed in most vertebrate species. It is produced by sub-periosteal apposition of lamellae which enclose primary canals. The individual canals are not surrounded by a broad, tubular sheath of concentric lamellae. Note that these canals are present in varying proportions in many other sections illustrated in this study. Femur, Rhesus monkey. $62 \times$. Decalcified and stained ground-section. 

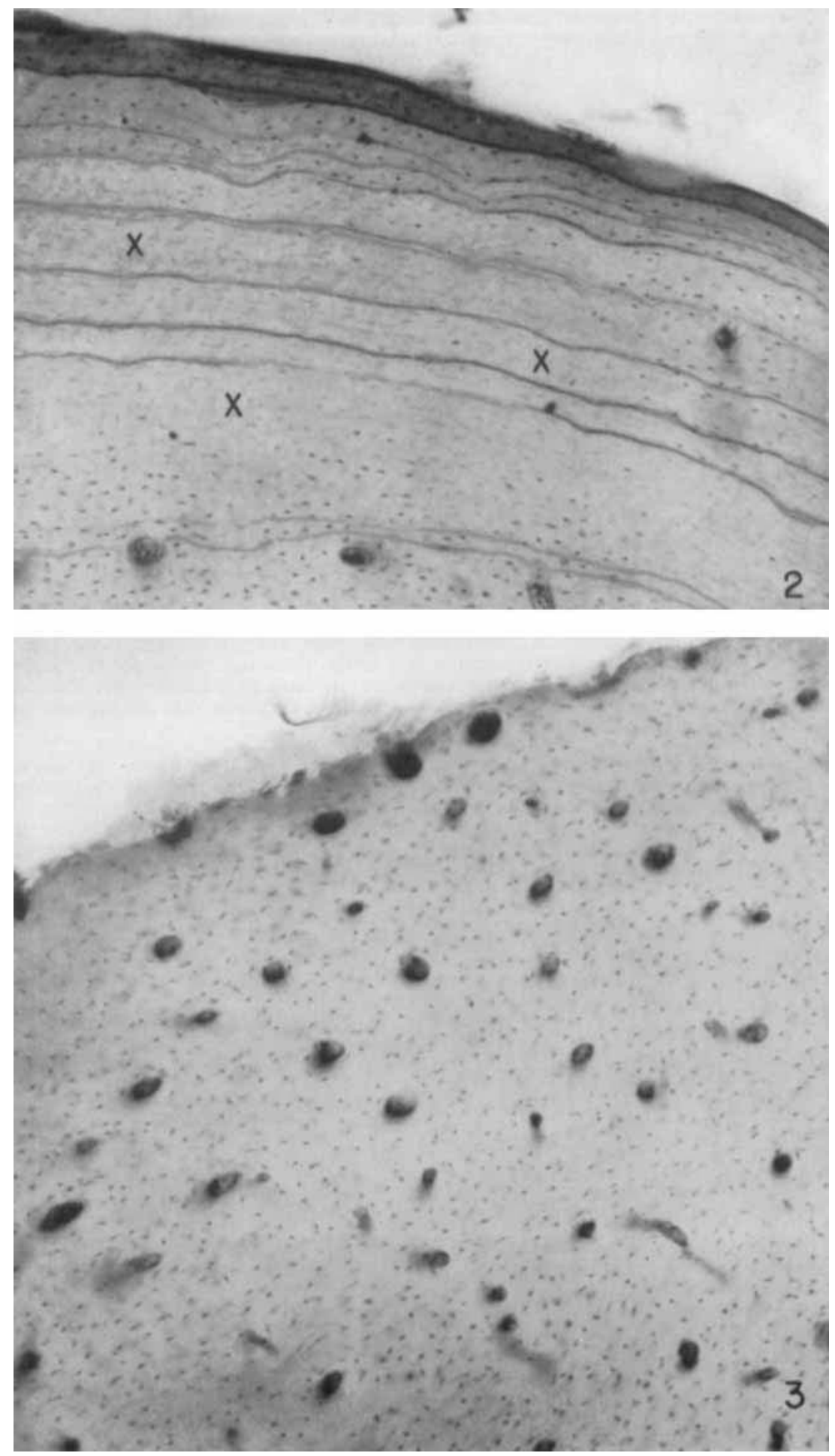


\section{PLATE 3}

EXPLANATION OF FIGURES

4 Secondary osteones (A) and resorption canal (B) in an extensive zone of osteocyte necrosis $(X)$. The interstitial lacunae in this zone are all without osteocytes. Dark shadows appear in some of the lacunae due to the thickness of the section and do not represent nuclei. The lacunae of the secondary osteones do contain cells. Osteocytes in the richly vascular zone (D) have not experienced necrosis. Femur, Rhesus monkey. $68.9 \times$. Stained and decalcified preparation.

5 Enlarged view of the area of secondary reconstruction seen in figure (4) above. The resorption canal (B) has formed within the area of osteocyte necrosis (X). Deposition of concentric Haversian lamellae within such spaces has resulted in the formation of secondary osteones (A) which are now superimposed over the older bone. Note that the lacunae surrounding primary canals (C) in this region are entirely empty of cells. Femur, Rhesus monkey. $106 \times$. Decalcified and stained preparation. 

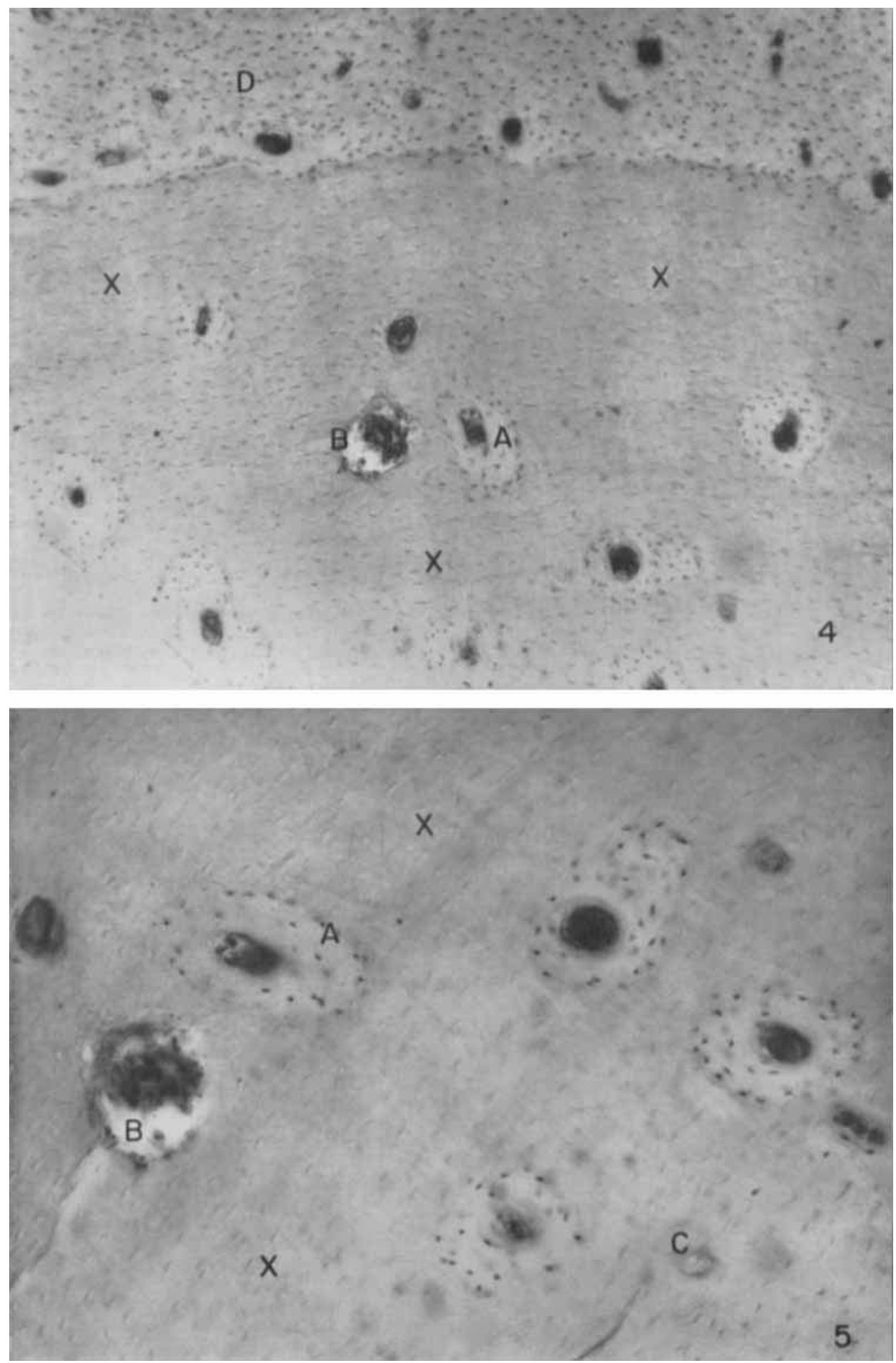
PLATE 4

EXPLANATION OF FIGURES

6 Resorption canal (A) and secondary osteones (C) located in a restricted region of necrosis $(x)$. Note that the lacunae around several of the primary vascular canals are empty (B). Femur, Rhesus monkey, $58 \times$. Decalcified and stained ground-section.

7 Resorption spaces (A) and secondary osteones in an area of necrosis ( $x$ ). Femur, dog. $43.5 \times$. Decalcified and stained ground-section.

8 Haversian bone located in a tubercle. Note the secondary osteone (A) as it enters the previously established compact bone from the external periosteal surface. The lamellar wall of this osteone was continuous with the periosteum. Humerus, Rhesus monkey. $58 \times$. Decalcified and stained ground-section. 

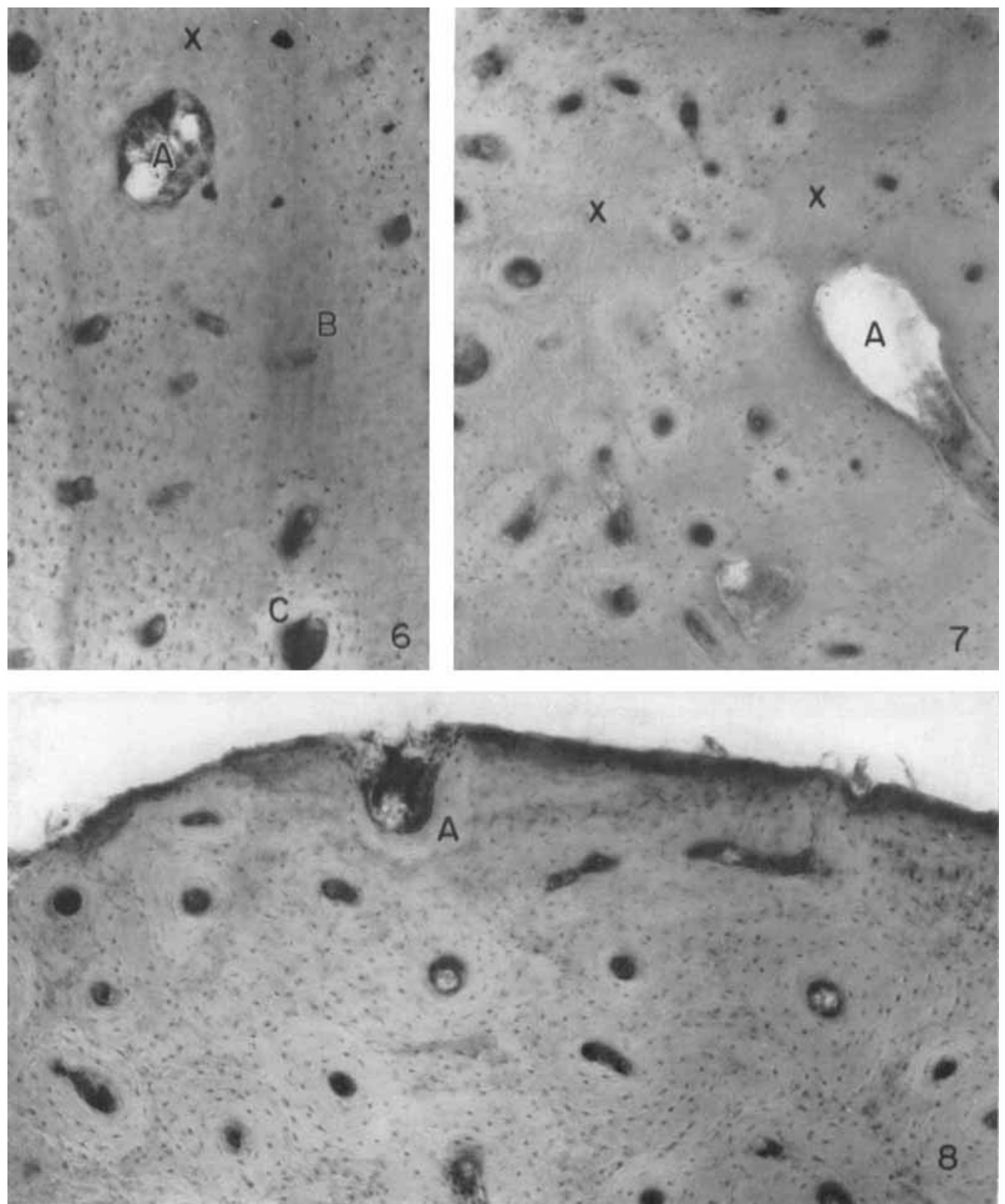


\section{PLATE 5}

EXPLANATION OF FIGURES

9 An external layer of small, primary osteones in the formative stage. With subsequent deposition of outer circumferential lamellae, this layer will form a thin "zone" when it later becomes embedded in the cortex. Femur, Rhesus monkey. $62 \times$. Decalcified and stained ground-section.

10 Necrosis ( $x$ ) in a circumferential layer of compact bone. Note that the empty lacunae are located in areas which are distant from vascular supply. Femur, dog $62 \times$. Decalcified and stained ground-section. 


PLATE 6

EXPLANATION OF FIGURES

11 "Plexiform" bone, a frequent variety of primary bone tissue found in certain vertebrate groups, including some carnivores and most artiodactyls. Mid-diaphyseal section of the femur, transverse section, dog. $56 \times$. Decalcified and stained ground-section.

12 Secondary osteones in an area of muscle attachment. Note the resorption space (A) in an adjacent zone of necrosis ( $x$ ). The secondary osteones in the tubercle itself (B) did not form as a response to necrosis. Femur, Rhesus monkey. $56 \times$. Decalcified and stained ground-section. 

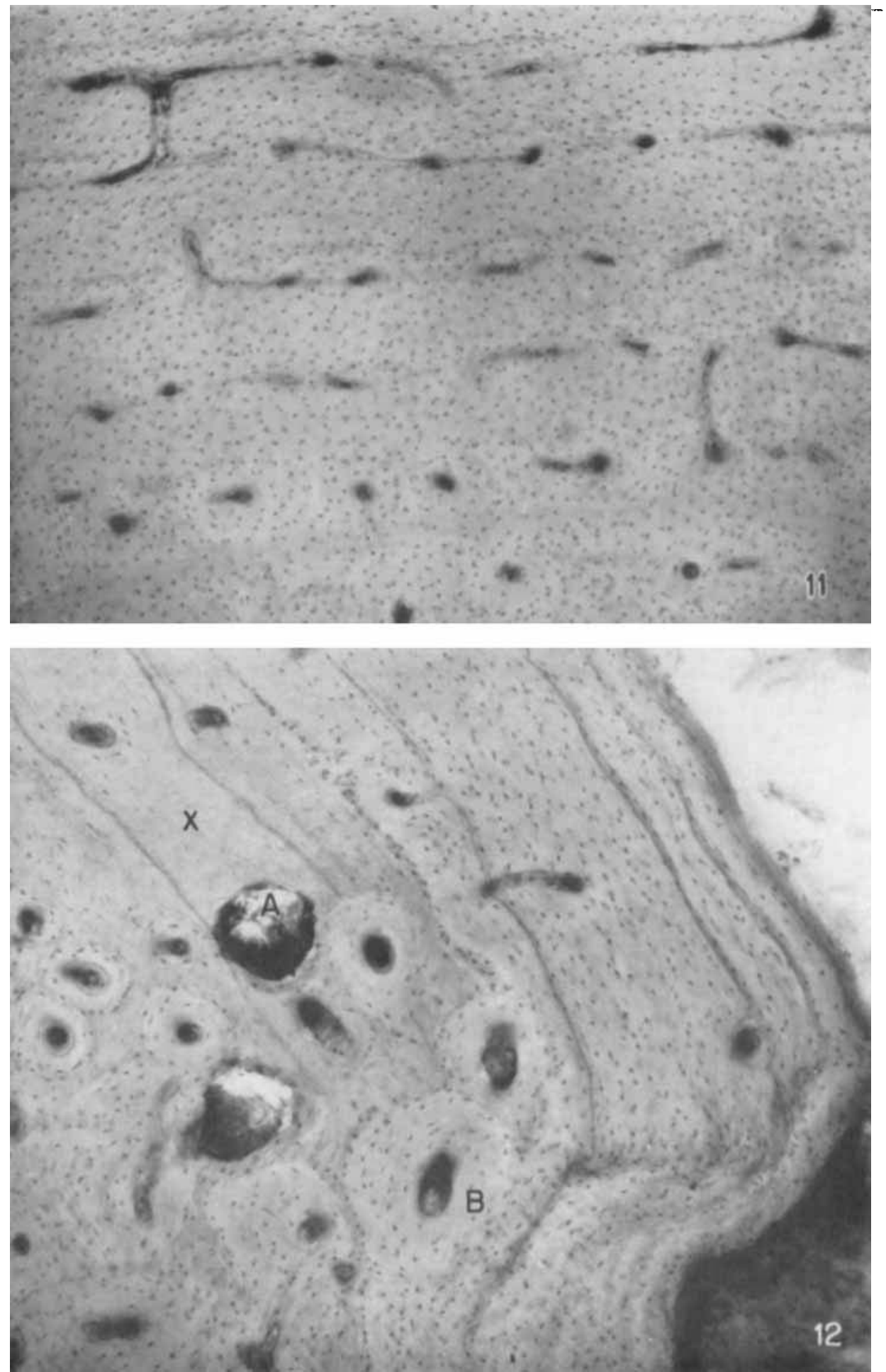
PLATE 7

EXPLANATION OF FIGURES

13 Secondary osteones in an area of muscle attachment. Note that the tubercle is "drifting" from side (B) to side (A) and that the secondary osteones (D) and resorption spaces (C) have developed from primary, non-Haversian canals ( $E$ ) in the direction of the drift. Humerus, Cercopithecus. $57 \times$. Decalcified and stained ground-section.

14 Secondary osteones associated with endosteal growth. The compaction of coarsecancellous bone and periosteal anchorage are both involved. Note the irregular contours of the interstial bone. Following reversal in direction of growth, outer circumferential lamellae (arrows) form a broad zone which now encloses the older endosteal zone. Femur, Rhesus monkey. $57 \times$. Decalcified and stained ground-section. 

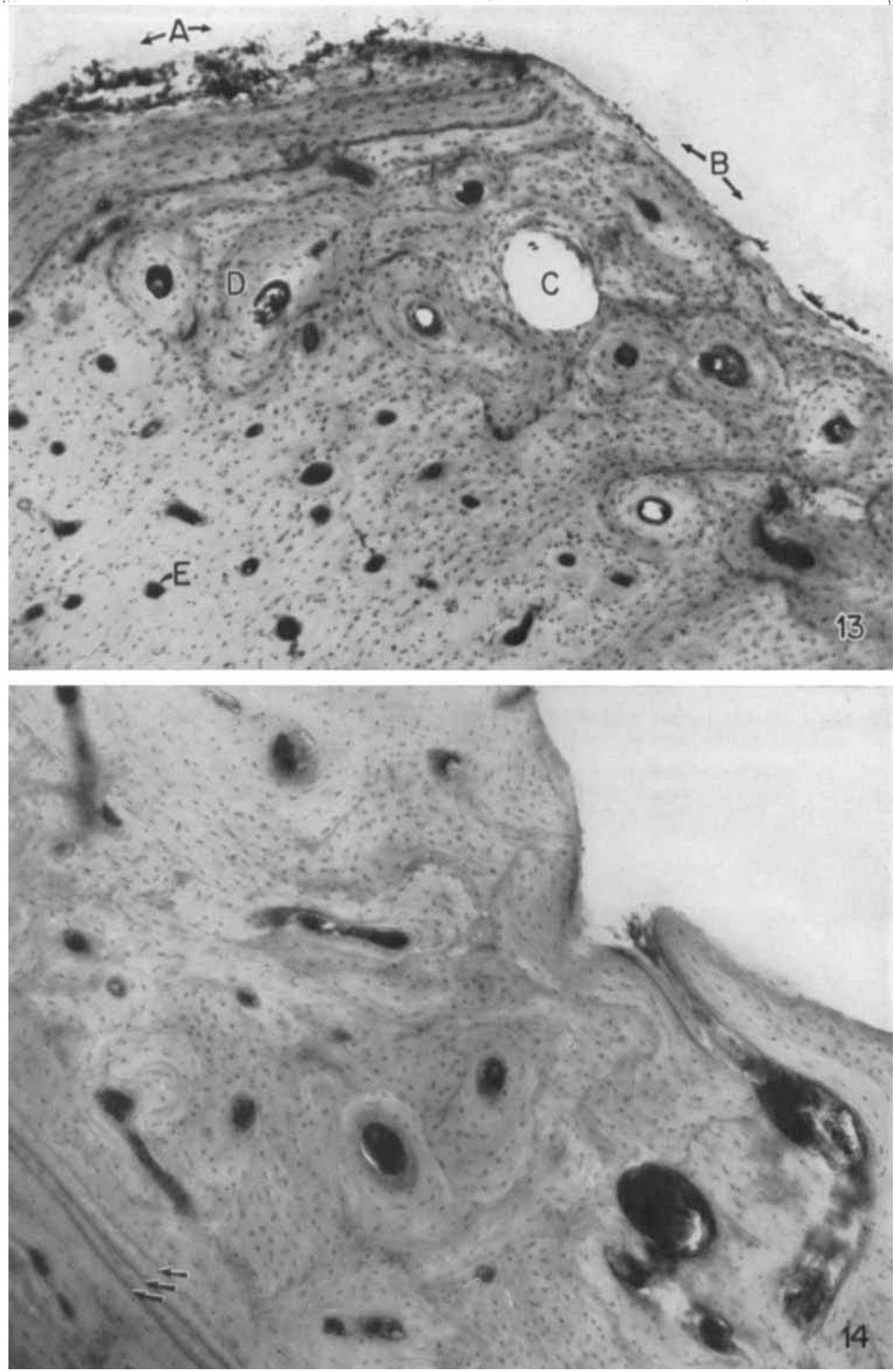


\section{PLATE 8}

EXPLANATION OF FIGURES

15 Irregular patches of canalicular calcification containing superimposed resorption spaces (B) and secondary osteones (A). Femur, Rhesus monkey. $12.3 \times$. Ground-section.

16 Necrotic areas involving canalicular calcification (micropetrosis) can be identified by their lighter, transparent appearance (A). Femur, Rhesus monkey. 12.3 $\times$. Ground. section.

17 Extensive interstitial micropetrosis between first and second generations of secondary osteones. Tibia, human. $12.3 \times$. Ground-section.

18 Patches of micropetrosis showing partial replacement by secondary osteones (B). Note the peripheral zone of circumferential micropetrosis (A) and the sparse distribution of canals. Tibia, Rhesus monkey. 12.3. Ground-section. 


PLATE 9

EXPLANATION OF FIGURES

19 Secondary osteones in patches of micropetrotic bone in a species from a vertebrate group rarely possessing dense, secondary Haversian tissues. Femur, Gopher Tortoise (Gopherus). $22.8 \times$. Ground-section.

20 Microradiograph of the same area as (21) below. Note that micropetrosis does not affect the overall density of the interstitial matrix between osteones. $22.8 \times$.

21 Secondary osteones located within an area of micropetrotic bone. Femur, Rhesus monkey. $22.8 \times$. Ground-section.

22 This is the "classic" arrangement of bone tissue structure. A zone of periosteal circumferential lamellae (A) encloses two zones of endosteal bone, (B) and (C). Zone (B) is the result of secondary Haversian reconstruction which was involved with inward growth during decrease in the diameter of the shaft. Note the irregular, convoluted contours of the interstitial bone in this area. Zone (C) is composed of inner circumferential lamellae. It is the structural result of endosteal deposition which did not involve cancellous compaction, since coarse-cancellous trabeculae are reduced in number or absent in the middle third of the diaphysis. Although this particualr arrangement of zones has been traditionally adopted as a standard, representative pattern of bone structure, it is important to realize that many other common patterns of arrangement may be found in compact bone tissue. Femur, Rhesus monkey, mid-diaphyseal transverse section. $57 \times$. Ground preparation. 

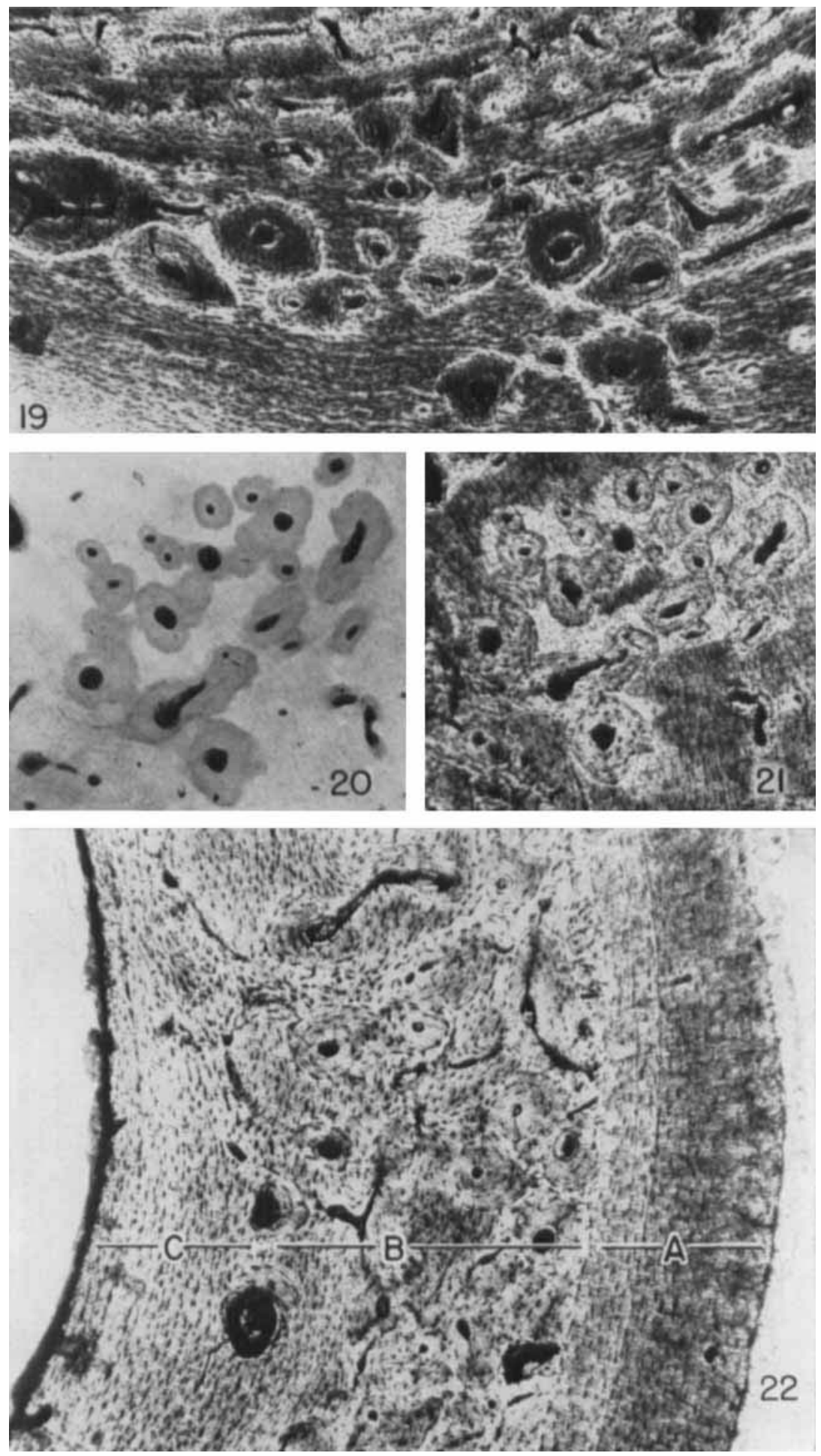
PLATE 10

EXPLANATION OF FIGURES

23 Area of muscle attachment in the femur of the Rhesus monkey. Note the concentration of secondary osteones (A) in this specific region. Canals lateral to the tubercle on both sides are primary non-Haversian canals (B). Bundles of Sharpey's fibers can be seen in the interstitial areas. $20.8 \times$. Ground-section.

24 Secondary osteones located within patches of micropetrotic bone. Femur, Rhesus monkey. $72.8 \times$. Ground-section. 

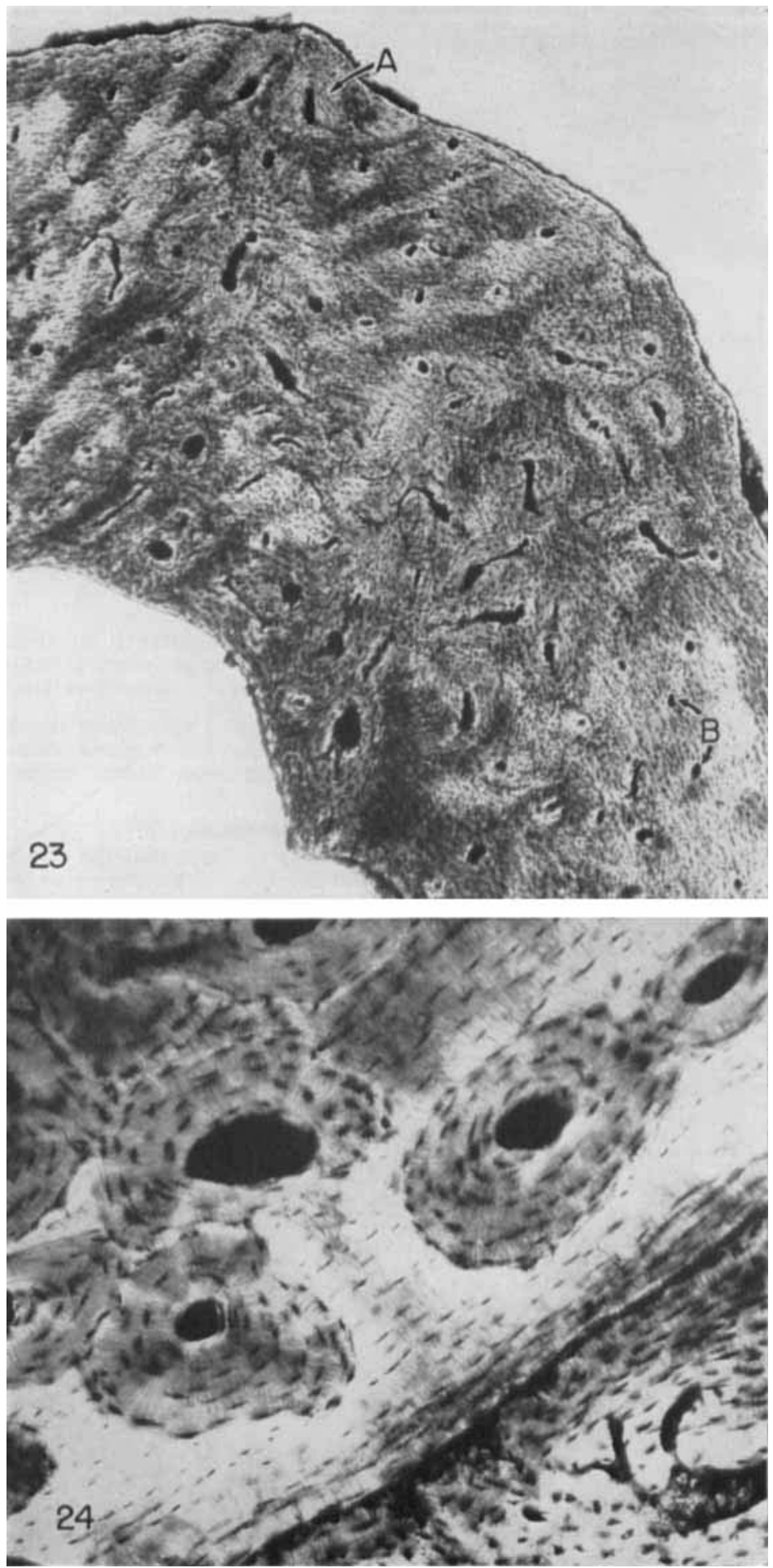
PLATE 11

EXPLANATION OF FIGURES

25 Compaction of coarse cancellous bone during endosteal growth in the metaphysis. Secondary osteones have formed as a result of progressive periosteal invasion of the inwardly shifting cortex. Humerus, Rhesus monkey. $26.1 \times$. Ground-section.

26 Resorption canal in experimentally induced necrotic bone (B). Note the deposition of some concentric lamellae within the canal. The external layers of the cortex (A) represent a callus which has enclosed the area of cauterized bone. Femur, white rat. $49.3 \times$. Ground-section.

27 Progressive formation of secondary osteones during decrease in metaphyseal diameter. Note that the external surface is undergoing resorption, and that the endosteal surface (lower part of the figure) is receiving lamellar deposits. Development of the Haversian systems (A) and resorption spaces (B) has proceeded in an inward direction. The same canals become primary (C) toward the inner third of the cortex. Radius, Rhesus monkey. $69.6 \times$. Ground-section. 

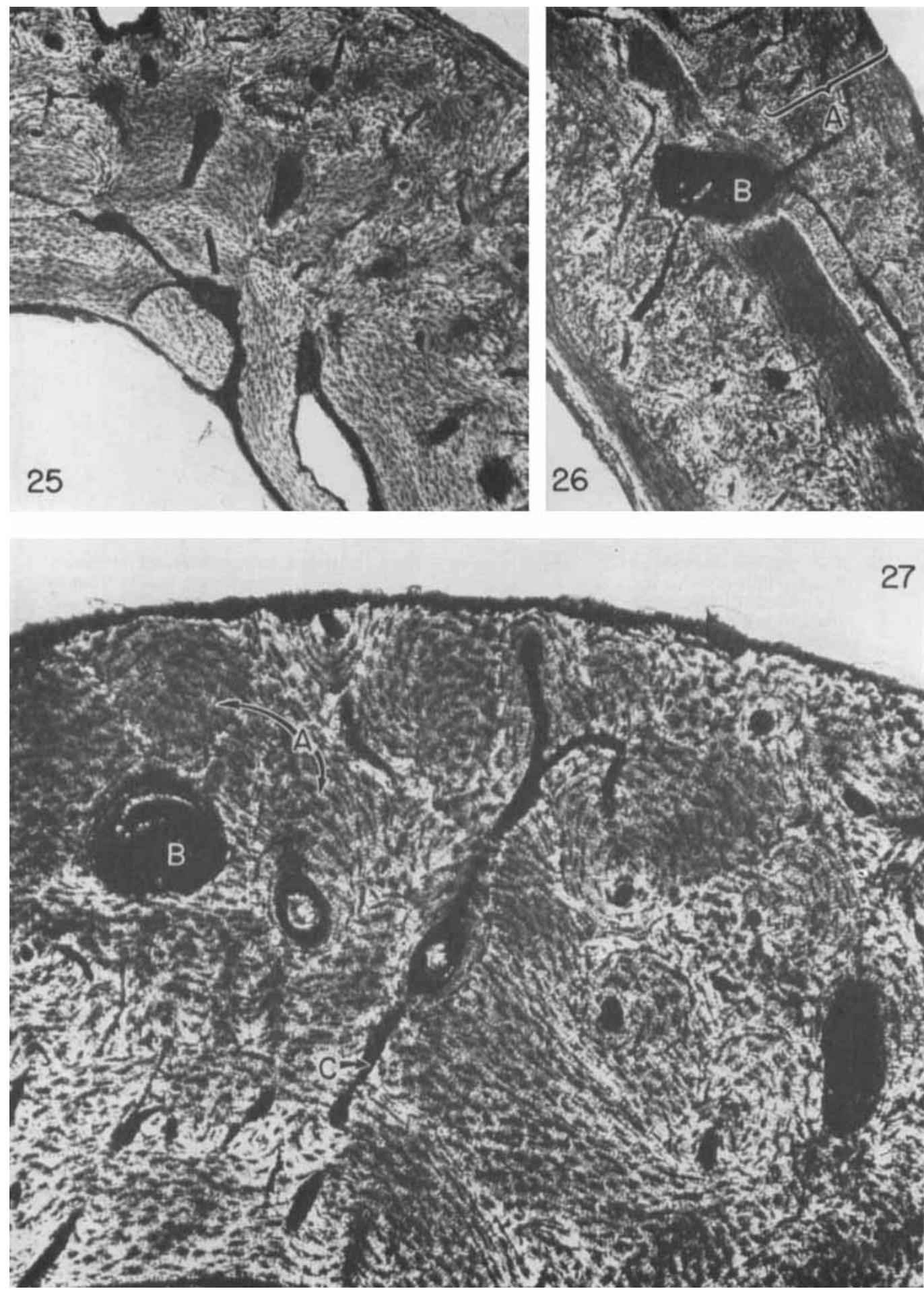
PLATE 12

EXPLANATION OF FIGURES

28 This pattern is produced by inward growth during reduction in metaphyseal diameter. Compaction of cancellous bone is not involved, and endosteal deposits are in the form of circumferential lamellar sheets (A). A broad zone of secondary osteones (B) has developed within the outer part of this endosteal bone. Humerus, Rhesus monkey. $53 \times$. Ground-section.

29 Following periosteal reversal in direction of growth, the arrangement seen in the previous figure (28) will now have the pattern seen in this section. The zone of secondary Haversian tissue (B), formerly located on the outside of the cortex, forms an inner zone following periosteal deposition of outer circumferential lamellae (A). This arrangement is commonly observed in the middle third of the bone. Femur, Rhesus monkey. $53 \times$. Ground-section. 

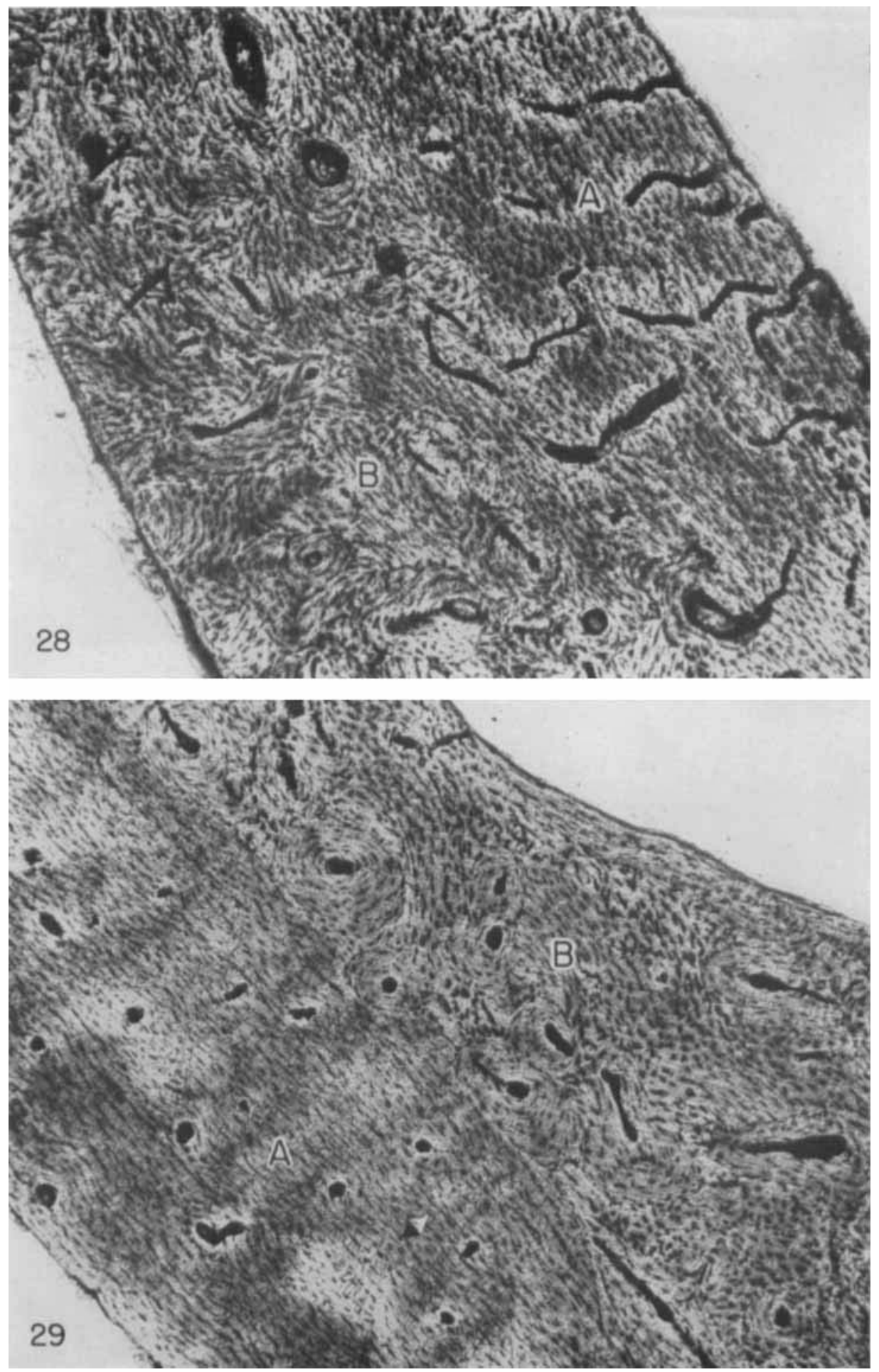